\title{
Quantitative detection of fecal contamination with domestic poultry feces in environments in China
}

\author{
Fang-Fang Zhuang ${ }^{1,2}, \mathrm{Hu} \mathrm{Li}^{1}$, Xin-Yuan Zhou ${ }^{1}$, Yong-Guan Zhu ${ }^{1}$ and Jian-Qiang Su ${ }^{1 *}$ (D)
}

\begin{abstract}
Poultry are an important source of fecal contamination in environments. However, tools for detecting and tracking this fecal contamination are in the early stages of development. In practice, we have found that source tracking methods targeting the $16 \mathrm{~S}$ rRNA genes of poultry-specific microbiota are not sufficiently sensitive. We therefore developed two quantitative PCR assays for detection of poultry fecal contamination, by targeting chicken and duck mitochondrial genes: NADH dehydrogenase subunit 5 (ND5) and cytochrome $b$ (cytb). The sensitivity of both assays was 100\% when tested on 50 chicken and duck fecal samples from 10 provinces of China. These assays were also tested in field samples, including soil and water collected adjacent to duck farms, and soils fertilized with chicken manure. Poultry mitochondrial DNA was detected in most of these samples, indicating that the assays are a robust method for monitoring environmental contamination with poultry feces. Complemented with existing indicators of fecal contamination, these markers should improve the efficiency and accuracy of microbial source tracking.
\end{abstract}

Keywords: Poultry, Source tracking, Pollution, Mitochondrial DNA, Quantitative PCR, Human impacts

\section{Introduction}

Animal and human feces carry many enteric pathogens, and when these contaminate water bodies, they pose a risk to human health (WHO Scientific group 2011; Harwood et al. 2014). Contamination with feces is a global public health issue from the perspective of the microbiological safety of water (Simpson et al. 2002; Blanch et al. 2006). However, detection and identification of pathogens is time-consuming and costly, due to the diversity and low concentrations of pathogens in environments (Field and Samadpour 2007). Instead, the presence of pathogens is often assumed based on detection of fecal indicator bacteria (FIB) including fecal coliforms and enterococci. These microorganisms are found in many animals and can survive and reproduce

\footnotetext{
*Correspondence: jqsu@iue.ac.cn

${ }^{1}$ Key Lab of Urban Environment and Health, Institute of Urban Environment, Chinese Academy of Sciences, 1799 Jimei Road, Xiamen 361021, China

Full list of author information is available at the end of the article
}

in diverse environments (Harwood et al. 2014). Thus, the source, and extent of pollution with FIB can be difficult to identify.

Domestic chickens and ducks are common around the world, and especially so in China. Commercial and backyard poultry farming both result in discharge of poultry feces into the environment, particularly after storms and floods. In addition, poultry manure is frequently applied to agricultural fields as fertilizer (Ryu et al. 2014). Poultry feces are known to carry human pathogens (McMurry et al. 1998; Hofacre et al. 2000), and consequently, attention needs to be paid to pollution with poultry feces. In particular, robust assays are needed to monitor environments in the interest of public health.

Microbial source tracking (MST) methods (Wiggins 1996; Parveen et al. 1997) use host-specific genetic markers as alternative indicators of fecal contamination from various sources (Scott et al. 2002). MST markers have been developed for identifying the source of fecal pollution by targeting the 16S rRNA genes and other genes of host-associated microbiota, or by targeting host-specific mitochondrial DNA (mtDNA). 
MST methods for humans and other animals such as pigs, dogs, and cattle are well developed. In contrast, real-time PCR assays targeting domestic chickens and ducks are not well established. Poultry-specific source tracking markers have been developed, but these assays mostly target chicken (Schill and Mathes 2008; GómezDoñate et al. 2012; Kobayashi et al. 2013; Dancer et al. 2014; Ryu et al. 2014; Ohad et al. 2016). Further, $16 \mathrm{~S}$ rRNA markers for 'host-specific' microorganisms often cross-react with the microbiota of other animals (Layton et al. 2006; Kildare et al. 2007; Marti et al. 2011; Ryu et al. 2012; Boehm et al. 2013; Green et al. 2014a). Functional genetic markers for host-specific microorganisms often have issues with sensitivity (Ebentier et al. 2013). In our hands, source tracking markers targeting enteric microbial genes of chicken and poultry showed low sensitivity and were not effective for detecting fecal contamination from poultry. Methods based on species-specific eukaryotic mtDNA markers might show more promise for fecal source tracking (Caldwell et al. 2011).

The objective of this study was to develop real-time PCR assays that targeted chicken and duck mtDNA with high sensitivity and specificity. Two novel assays were developed targeting poultry mitochondrial genes: NADH dehydrogenase subunit 5 (ND5) and cytochrome $b$ (cytb). We test 173 fecal samples from 12 host species to test the performance of the two assays. Subsequently, the assays were applied to environmental soil and water samples.

\section{Materials and methods}

\section{Sample collection}

A total of 173 fecal samples were collected between August 2015 and July 2016 from 14 provinces of China, including Inner Mongolia, Beijing, Hebei, Tianjin, Shandong, Shanxi, Jiangsu, Zhejiang, Jiangxi, Fujian, Guangdong, Tibet, Hong Kong, and Hainan Province. Fecal samples were from a variety of host animals, including chickens $(\mathrm{n}=38)$, ducks $(\mathrm{n}=9)$, poultry (chicken and duck composite fecal samples, $\mathrm{n}=3$ ), humans $(\mathrm{n}=25)$, pigs $(\mathrm{n}=17)$, dogs $(\mathrm{n}=23)$, cattle $(\mathrm{n}=17)$, sheep $(n=16)$, cats $(n=5)$, horses $(n=8)$, deer $(n=1)$, geese $(\mathrm{n}=2)$, and rabbits $(\mathrm{n}=9)$. Fresh feces were frozen and transported on ice to the laboratory within 3 days. All samples were stored at $-20^{\circ} \mathrm{C}$ until use.

Soil and water samples from eight duck farms in Yizhou of Guangxi Province and one duck farm in Longyan of Fujian Province were collected in September 2016. Samples were immediately frozen at $-20^{\circ} \mathrm{C}$ and transported on ice to the laboratory within $24 \mathrm{~h}$.

Soils fertilized with chicken manure (CM) were collected from a long-term experiment station of the Chinese Academy of Agricultural Sciences (CAAS) in
Dezhou, Shandong Province. A total of 24 samples from eight treatments in triplicate were collected in August 2015, about ten months after the application of chicken manure, urea or sewage sludge. One treatment was fertilized with chicken manure, and the other seven treatments were fertilized with urea or sewage sludge. The soils were immediately frozen on dry ice, transported to the laboratory within $24 \mathrm{~h}$ and stored at $-80{ }^{\circ} \mathrm{C}$ until analysis. Details on the design of this field experiment are described by Chen et al. (2016).

\section{Sample pretreatment and DNA extraction}

Water samples $(0.5 \mathrm{~L})$ were filtered through $0.22-\mu \mathrm{m}$ mixed cellulose ester membrane, which were cut into small pieces using aseptic scissors and placed into Lysing Matrix tubes provided in the FastDNA ${ }^{\circledR}$ SPIN Kit for Soil (MP Biomedical, Santa Ana, California, USA). Total DNA of soil and water samples was extracted according to the manufacturer's protocol. Total DNA of fecal samples was extracted from $0.5 \mathrm{~g}$ frozen samples using FastDNA ${ }^{\circledR}$ SPIN Kit for Feces (MP Biomedical, Santa Ana, California, USA), following the manufacturer's instructions. The quality and quantity of DNA were analyzed by spectrophotometry using NanoDrop ND-1000 (Nanodrop, USA). The extracted DNA was stored at $-20{ }^{\circ} \mathrm{C}$.

\section{Primer and probe design}

Multiple alignments of the target host mtDNA (Fig. 1) were performed using the program Clustal X (Larkin et al. 2007). Nucleotide sequences were retrieved from NCBI GenBank ${ }^{\mathrm{TM}}$ under accession numbers: chicken (L08376 and EF493865), duck (KF156760), human (AP009462 and AY063385), cattle (D34635, and GQ129208), dog (KU253532 and JX088690), pig (AB015081 and AF034253), sheep (KP228916 and DQ320085), goat (KP273589), cat (AB004238 and NC_001700), horse (D82932 and HQ439469), goose (NC_011196). New primers and probes for mitochondrial genes NADH dehydrogenase subunit 5 (ND5) and cytochrome $b(c y t b)$ for chicken and duck (Table 1) were designed manually, and then confirmed with OligoAnalyzer software from IDT (Owczarzy et al. 2008). Minor groove binder (MGB) probes were designed for chicken and duck ND5, and chicken and duck cytb markers. The 6-carboxy-fluorescein (FAM) was conjugated at the $5^{\prime}$ ends of the MGB probes, and a non-fluorescent quencher (NFQ) was conjugated at the $3^{\prime}$ ends. Primers were synthesized by Invitrogen (Carlsbad, CA, USA) and TaqMan probes were synthesized by Applied Biosystems (Foster City, CA, USA). All oligonucleotides were reconstituted in TE buffer ( $\mathrm{pH} 7.5$ ) and stored at $-20{ }^{\circ} \mathrm{C}$ prior to use. 


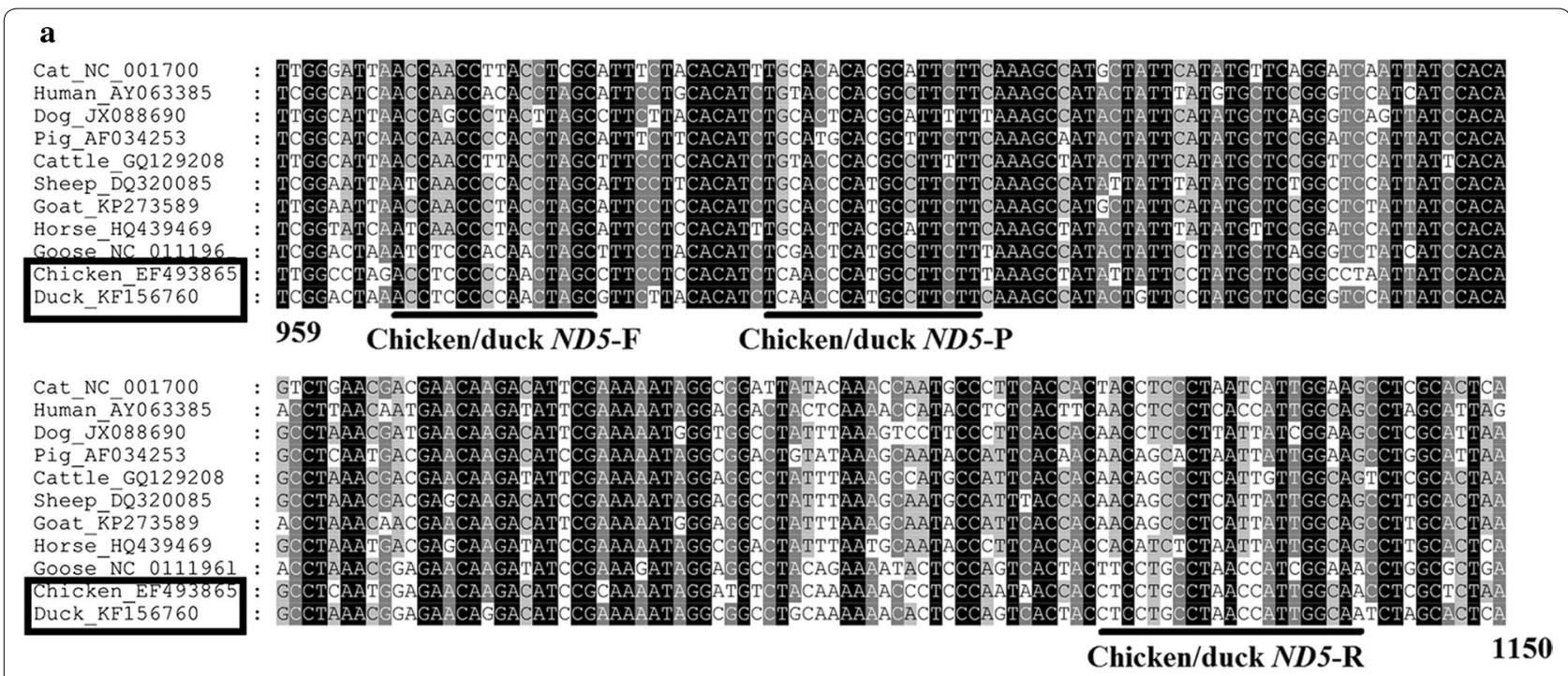

b

Cat_AB004238 Human_AP009462 Dog_Kū 253532 Pig_AB015081 Catťle_D34635 Sheep_KP228916 Goat_KP273589 Goose ${ }^{-}$C 011196 Chicken_L08376
Duck_KF156760

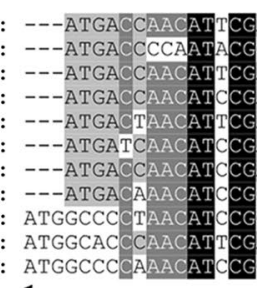

1

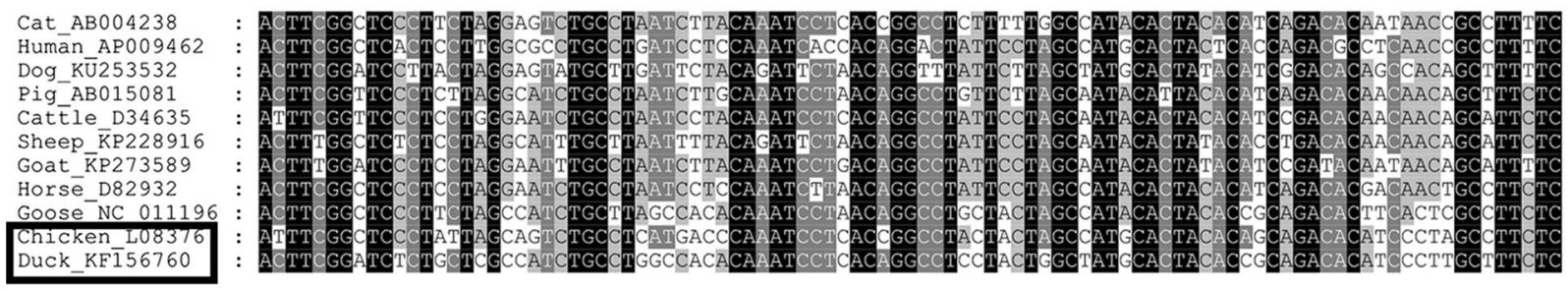

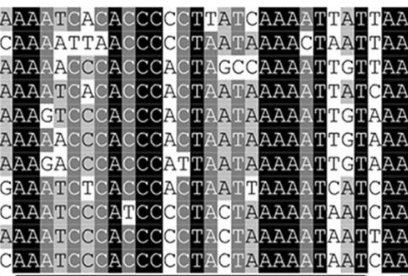

Chicken/duck $c y t b-F \quad$ Chicken/duck $c y t b-P$

Cat_AB004238 Humān AP009462 Dog_Kप̄ 253532 Pig_AB015081 Catt̄le_D34635

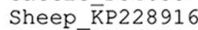
Goat_ǨP273589 Horse_D82932

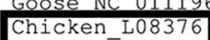
Chicken -108376
Duck KF156760
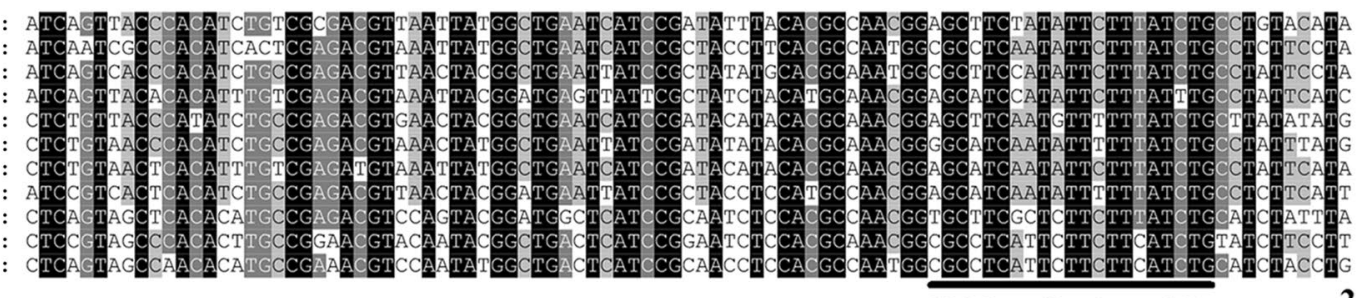

Chicken/duck cytb-R

Fig. 1 Alignments of mtDNA ND5 and cytb gene from cat, human, dog, pig, cattle, sheep, goat, horse, goose, chicken, and duck. Binding sites of primers and probes to the mtDNA ND5 and cytb gene sequences are indicated. $\mathbf{a}$ mtDNA ND5 assay and $\mathbf{b}$ mtDNA cytb assay

\section{Standard curve generation}

To make standard plasmids, the purified chicken and duck ND5 and $c y t b$ gene products of traditional PCR were cloned using the pMD19-T vector (Takara, Bio Inc., Shiga, Japan), and were then sequenced. The plasmids with correct target genes were extracted using TIANprep MINI plasmid kit (Tiangen, Beijing, China). Standard curves of chicken and duck ND5 and $c y t b$ were generated using tenfold serial dilutions $\left(9.70 \times 10^{7}-10^{0}\right.$ and $1.08 \times 10^{8}-10^{1}$ copies per $\mu \mathrm{L}$ respectively) of 
Table 1 Oligonucleotide sequences for quantitative PCR

\begin{tabular}{|c|c|c|c|}
\hline Primer or probe & Oligonucleotide sequence $\left(5^{\prime}-3^{\prime}\right)$ & $\operatorname{Tm}\left({ }^{\circ} \mathrm{C}\right)$ & Amplicon size (bp) \\
\hline Chicken and duck ND5-F & ACCTCCCCCAACTAGC & 53.6 & 172 \\
\hline Chicken and duck ND5-R & TTGCCAATGGTTAGGCAGGAG & 57.7 & \\
\hline Chicken and duck ND5-P & (FAM)TCAACCCATGCCTTCTT(NFQ-MGB) & 61.1 & \\
\hline Chicken and duck cytb-F & AAATCCCACCCCCTACTAAAAATAAT & 54.3 & 263 \\
\hline Chicken and duck cytb-R & CAGATGAAGAAGAATGAGGCG & 53.4 & \\
\hline Chicken and duck cytb-P & (FAM)ACAACTCCCTAATCGACCT(NFQ-MGB) & 62.7 & \\
\hline
\end{tabular}

standard plasmids containing chicken and duck ND5 or $c y t b$ genes.

\section{Quantitative PCR}

Chicken and duck ND5 and cytb gene abundances were determined by qPCR using the LightCycler 480 real-time PCR detection system (Roche480, USA). A $20 \mu \mathrm{L}$ aliquot of qPCR mixture contained $10 \mu \mathrm{L}$ of $2 \times$ TaqMan $^{\circledR}$ Gene Expression Master Mix (Applied Biosystems, Foster City, CA, USA), $0.9 \mu \mathrm{M}$ each of forward and reverse primers, $0.25 \mu \mathrm{M}$ of TaqMan probe, $1 \mathrm{mg} \mathrm{mL} \mathrm{m}^{-1}$ of bovine serum albumin (BSA, Sigma, Steinheim, Germany), 20-100 ng template DNA, and sterile $\mathrm{ddH}_{2} \mathrm{O}$. The qPCR was conducted with the following conditions: $50{ }^{\circ} \mathrm{C}$ for $2 \mathrm{~min}$ (activation of the uracil-N-glycosylase) and $95{ }^{\circ} \mathrm{C}$ for $10 \mathrm{~min}$ (activation of the AmpliTaq Gold DNA polymerase), followed by 40 cycles of denaturation at $95^{\circ} \mathrm{C}$ for $15 \mathrm{~s}$ and annealing and extension at $60{ }^{\circ} \mathrm{C}$ for $1 \mathrm{~min}$. No template controls were used for all assays. All samples, standards, and controls were run in triplicate. A sample was classified as quantifiable if two or more replicates were above the limits of detection (LOD). Only amplification efficiencies between 85 and $115 \%$ were considered as acceptable for quantification.

\section{Statistical analysis}

Amplification efficiency $(E)$ was determined using the slope of the standard curve, as follows: $E=10^{(-1 /}$ slope) -1 . The LOD was defined as the lowest concentration of the marker within the linear range of a quantification curve. Sensitivity was calculated as the fraction of actual positive [true positive (TP)] host samples divided by all expected positive hosts, including both false negative (FN) and TP, as follows: Sensitivity = TP/ $(\mathrm{FN}+\mathrm{TP})$. Specificity was calculated as the fraction of actual negative [true negative (TN)] host samples divided by all expected negative hosts including both unexpected positive [false positive (FP)] and TN, as follows: Specificity $=\mathrm{TN} /(\mathrm{FP}+\mathrm{TN})$.

\section{Results}

Design of chicken and duck-specific mtDNA ND5 and cytb genetic markers

Multiple alignments of mtDNA ND5 and cytb gene from cat, human, dog, pig, cattle, sheep, goat, horse, goose, chicken, and duck were performed using Clustal X. We designed two assays targeting chicken and duck mtDNA ND5 and $c y t b$ gene, the expected amplicon sizes being 172 and $263 \mathrm{bp}$, respectively (Table 1). Based on the multiple alignments, chicken and duck ND5 and cytb could be readily differentiated from the other selected hosts (Fig. 1).

\section{qPCR assays}

Standard curves were generated using tenfold serial dilutions of chicken and duck ND5 and cytb gene standard plasmids to determine the linear range, amplification efficiencies, and LOD. Linear range amplification was between $9.70 \times 10^{0}-10^{7}$ copies per $\mu \mathrm{L}$ for the ND5 assay and $1.08 \times 10^{1}-10^{8}$ copies per $\mu \mathrm{L}$ for the $c y t b$ assay. The linear regression correlation coefficients $\left(R^{2}\right)$ were 0.9993 for the ND5 assay and 0.9989 for the $c y t b$ assay. Amplification efficiency was 0.997 for the ND5 assay and 0.964 for the $c y t b$ assay, both of which were within the 0.9-1.1 tolerance. The LOD was 0.97 and 1.08 gene copies per reaction for the ND5 and $c y t b$ assays, respectively. Sensitivity and specificity of the assays were tested using total DNA extracted from 173 fecal samples of 12 common animals (Table 2).

The sensitivity of the ND5 assay was $100 \%$, with $50 / 50$ samples generated strong positive results. The quantified values (average \pm standard deviation) of these samples were $7.8 \pm 0.8 \log _{10}$ copies per g dry feces. Positive results were also obtained from some human, dog, cattle, horse, and goose feces samples, but the average quantified values for these samples were all one to two orders of magnitude lower than those for chicken and duck samples (Table 2). If these lower quantification values are included as genuine positives, the specificity of the ND5 assay was $84.6 \%$. 
Table 2 qPCR results of fecal samples from various host

\begin{tabular}{|c|c|c|c|c|c|}
\hline \multirow[t]{2}{*}{ Fecal samples } & \multirow[t]{2}{*}{ Number of samples } & \multicolumn{2}{|l|}{ ND5 assay } & \multicolumn{2}{|l|}{ Cytb assay } \\
\hline & & Positive & Concentration $^{a}$ & Positive & Concentration $^{a}$ \\
\hline Chicken and duck & 50 & $100 \%(50 / 50)$ & $7.8 \pm 0.8$ & $100 \%(50 / 50)$ & $7.4 \pm 0.8$ \\
\hline Human & 25 & $40 \%(10 / 25)$ & $5.6 \pm 0.4$ & $28 \%(7 / 25)$ & $5.2 \pm 0.3$ \\
\hline Pig & 17 & $0 \%$ & & $0 \%$ & \\
\hline Dog & 23 & $17.3 \%(4 / 23)$ & $5.2 \pm 0.8$ & $13.0 \%(3 / 23)$ & $4.9 \pm 0.6$ \\
\hline Cattle & 17 & $17.6 \%(3 / 17)$ & $5.9 \pm 1.4$ & $11.8 \%(2 / 17)$ & $6.1 \pm 1.4$ \\
\hline Sheep & 16 & $0 \%$ & & $0 \%$ & \\
\hline Cat & 5 & $0 \%$ & & $0 \%$ & \\
\hline Horse & 8 & $12.5 \%(1 / 8)$ & 5.5 & $12.5 \%(1 / 8)$ & 5.2 \\
\hline Deer & 1 & $0 \%$ & & $0 \%$ & \\
\hline Goose & 2 & $50 \%(1 / 2)$ & 6.1 & $50 \%(1 / 2)$ & 5.8 \\
\hline Rabbit & 9 & $0 \%$ & & $0 \%$ & \\
\hline
\end{tabular}

${ }^{a}$ Concentrations are expressed as log 10 copies per $\mathrm{g}$ dry feces

The sensitivity of the cytb assay was also 100\% (50/50 positives). The quantified values for these samples were $7.4 \pm 0.8 \log _{10}$ copies per g dry feces. Positive results were also obtained from some human, dog, cattle, horse, and goose feces, and these were the same samples as were found positive in the ND5 assay. This strongly suggests there was minor contamination with poultry DNA in at least some of the samples. Again, the average quantified values for these samples were all one to two orders of magnitude below that of the genuine poultry samples. The specificity of $c y t b$ assay was $89.8 \%$ if these low concentration positives are included in the calculation (Table 2).

\section{Application of qPCR assays on field samples}

We then applied the qPCR assays to environmental soil and water samples from nine duck farms and soils fertilized with chicken manure. All water samples tested positive using the ND5 assay, with copy numbers ranging from $2.8 \log _{10}$ copies per $100 \mathrm{~mL}$ to $6.4 \log _{10}$ copies per $100 \mathrm{~mL}$ water (Table 3). The cytb assay gave similar results, except for one Duck farm (YZ4), whose value was below the LOD. This sample had the lowest copy number using ND5 assay (Table 3).

One Yizhou soil sample from eight was positive with the ND5 and $c y t b$ assays, returning gene copy numbers of 5.1 and $4.6 \log _{10}$ copies per g dry soil, respectively. The Longyan soil sample was positive at the high concentrations of $8.1 \log _{10} N D 5$ gene copies per g dry soil and 8.0 $\log _{10} c y t b$ gene copies per g dry soil.

Both ND5 and cytb assays target mtDNA, and because the number of mtDNA molecules remains constant, the two assays should ideally return identical values for copy number in any particular sample. The values returned from analysis of feces, water and soil samples are in general agreement between the assays (Pearson correlation $\mathrm{r}=0.9828, \mathrm{P}<0.001)$, with the ND5 assay being consistently more sensitive (Tables 2,3 ).

Table 3 qPCR assays conducted on field samples, including soils amended with chicken manure (DZ-1CMDezhou), soil and water from duck farms in Longyan (LY) and Yizhou (YZ)

\begin{tabular}{|c|c|c|}
\hline Sample & ND5 assay ${ }^{\mathrm{a}}$ & Cytb assay ${ }^{a}$ \\
\hline$D Z-1 C M^{b}$ & 4.3 & 4.0 \\
\hline Duck farm water-LY & 6.4 & 5.9 \\
\hline Duck farm water-YZ1 & 3.6 & 3.1 \\
\hline Duck farm water-YZ2 & 4.0 & 3.2 \\
\hline Duck farm water-YZ3 & 4.4 & 3.8 \\
\hline Duck farm water-YZ4 & 2.8 & Not detected \\
\hline Duck farm water-YZ5 & 4.6 & 4.3 \\
\hline Duck farm water-YZ6 & 3.8 & 3.3 \\
\hline Duck farm water-YZ7 & 4.2 & 4.0 \\
\hline Duck farm water-YZ8 & 3.5 & 3.0 \\
\hline Duck farm soil-LY & 8.1 & 8.0 \\
\hline Duck farm soil-YZ1 & 5.1 & 4.6 \\
\hline Duck farm soil-YZ2 & Not detected & Not detected \\
\hline Duck farm soil-YZ3 & Not detected & Not detected \\
\hline Duck farm soil-YZ4 & Not detected & Not detected \\
\hline Duck farm soil-YZ5 & Not detected & Not detected \\
\hline Duck farm soil-YZ6 & Not detected & Not detected \\
\hline Duck farm soil-YZ7 & Not detected & Not detected \\
\hline Duck farm soil-YZ8 & Not detected & Not detected \\
\hline
\end{tabular}

a Concentrations are expressed in $\log 10$ copies per $\mathrm{g}$ dry soil or $\log 10$ copies per $100 \mathrm{~mL}$ water for environmental water samples

${ }^{b}$ qPCR results of the other seven treatments from Dezhou, including control and field soil amended with urea or sewage sludge, were below the LOD and not shown in the table 
Soil samples amended with chicken manure tested positive using both ND5 and cytb assays, returning concentrations of 4.3 and $4.0 \log _{10}$ copies per g dry soil respectively. This is despite sampling being undertaken 10 months after the application of manure. Seven other treatments taken from different plots in the same long term field experiment were below the LOD (data not shown). These plots had been amended with other fertilizers such as urea and sewage sludge.

\section{Discussion}

In this study, qPCR assays were developed to targeting chicken and duck mitochondrial ND5 and $c y t b$, with the aim of applying these for source tracking of poultry fecal contamination. Both assays were host-sensitive and hostspecific when tested with fecal samples, and were robust enough to be used for analyzing field samples of soil and water.

Using both assays in tandem allowed us to compare their efficiency, since they both target the same molecule, mtDNA. In general, these copy number estimates agreed between the assays, although the ND5 assay consistently returned slightly higher copy estimates (Tables 2,3 ). The amplification efficiency of the ND5 assay may have been higher. Because the size of ND5 amplicon (172 bp) was shorter than that of $c y t b$ amplicon (263 bp).

We tested 173 fecal samples from 12 hosts (Table 2) from a large geographical range in China. Both ND5 and $c y t b$ assays exhibited cross-reactions to some human, dog, cattle, horse and goose fecal samples. In general, the same samples were responsible for unexpected positives in both assays, suggesting that minor contamination might be responsible. In the case of human and dog fecal samples, this contamination might have arisen from recent consumption of poultry products. Positive signals for beef mtDNA ND5 were obtained from two out of four human volunteers who consumed beef within $24 \mathrm{~h}$ of sampling (Caldwell et al. 2007). In the same study, there was no carry-over signal from consumption of pork. Further studies are needed to confirm whether human consumption of poultry products results in poultry mtDNA being present in feces. We also detected a small number of unexpected positive signals from cattle, horse, and goose fecal samples, which might simply be from environmental cross-contamination of samples. In any case, these unexpected positives could be easily distinguished from genuine positive samples because copy number estimates were generally one to two orders of magnitude lower (Table 2).

In preliminary experiments, we tested five reported chicken and poultry markers, including CL-TaqMan (Ryu et al. 2014), PLprobe (Gómez-Doñate et al. 2012), Chicken/Duck-Bac (Kobayashi et al. 2013), Duck-Bac
(Kobayashi et al. 2013), and Av43 (Ohad et al. 2016), which target host-associated Brevibacterium sp., Bifidobacterium, Bacteroides spp., Bacteroides spp., and Firmicutes $16 \mathrm{~S}$ rRNA gene, respectively. It has been reported that CL-TaqMan, Chicken/Duck-Bac, and Duck-Bac assays showed relatively low sensitivity and specificity (Kobayashi et al. 2013; Ryu et al. 2014). Our results agreed with this conclusion. The sensitivity of CLTaqMan, PLprobe, Chicken/Duck-Bac, and Duck-Bac assays were all less than 50\%. PLprobe, Chicken/Duck$\mathrm{Bac}$, and Av43 assays exhibited cross-reactions with dog, cat, sheep, cow or pig feces (data not shown). The low sensitivity of markers might be caused by the low abundance of targeted microorganisms in the host feces, and microbiota might vary significantly with diet (Turnbaugh et al. 2009; Muegge et al. 2011; Wu et al. 2011; David et al. 2014).

Currently, most MST methods rely on fecal indicator microorganisms or use molecular methods that require extensive data collection before hosts can be reliably differentiated (Green et al. 2014b; McLellan and Eren 2014; Ohad et al. 2016). Our real-time PCR assays targeting poultry mtDNA genes can overcome the above disadvantages. Firstly, mtDNA is remarkable for its species-specificity and low intra-species variability (Moritz et al. 1987). It can thus be used to identify animal species directly rather than rely on microbial species which may, or may not occur in the animal host (Caldwell et al. 2007). Crucially, there are large numbers of epithelial cells shed in feces (Iyengar et al. 1991) and mtDNA has many gene copies per cell (Andreasson et al. 2002). Therefore, mtDNA genes are likely to generate robust signals, simply because of their abundance (Martellini et al. 2005). Thirdly, high abundance means a long halflife, and potential for persistence in environmental compartments. Several groups have reported mtDNA from human and dog feces can persist in water for 15-29 days (Martellini et al. 2005; Tambalo et al. 2012), and mtDNA markers can survive for relatively long time in water bodies (He et al. 2015). Finally, the mtDNA of most common species have been fully sequenced and are freely available.

Fecal contamination of water bodies is a common environmental problem (WHO Scientific group 2000; McLellan and Eren 2014). The qPCR assays we developed here were sensitive, having a detection limit of 0.97 and 1.08 gene copies per reaction for the ND5 and cytb assays, respectively (Table 2). This made it possible to readily identify poultry fecal contamination in environmental samples. We applied the ND5 and cytb assays to environmental soil and water samples from nine duck farms. All water samples were positive with the exception of one $c y t b$ assay. Two soil samples collected near duck farms detected poultry fecal pollution. For most soil samples, 
although the concentration of total DNA was high (data not shown), no poultry fecal contamination was detected. Density of farm is likely one of the factors for low detection rate. Another reason may due to the random distribution of duck feces in farm soil. Detection of fecal contamination in soil is more difficult to achieve due to the heterogeneity of soil, limitation in sample collection, and DNA extraction, since only a small fraction $(0.5 \mathrm{~g}$ in this study) of soil was subjected to DNA extraction and PCR amplification. In addition, contaminants in water are more mobilized than that in soil, leading to rapid spread in water bodies.

To test if this was because the mtDNA degraded more rapidly in soil, we tested soil where chicken manure had been applied. Samples taken ten months after the application of chicken manure were still positive in both assays, suggesting that the ND5 and $c y t b$ assays are robust enough to be used on field samples.

In conclusion, we developed qPCR assays targeting the chicken and duck mitochondrial ND5 and cytb genes. Both assays were sensitive and specific, as tested against 173 fecal samples from diverse animals. We also tested the assays on field samples, detecting poultry mtDNA soil and water samples adjacent to duck farms, and soil amended with chicken manure. Further studies are needed to investigate the low levels of unexpected positive reactions to some other fecal samples, in particular to test whether consumption of poultry results in mtDNA being present in human feces. Overall, the assays should be a useful addition to existing methods for detecting domestic chicken and duck fecal pollution.

\section{Abbreviations \\ ND5: NADH dehydrogenase subunit 5; cytb: cytochrome $b$; FIB: fecal indicator bacteria; MST: microbial source tracking; mtDNA: mitochondrial DNA; CM: chicken manure; MGB: minor groove binder; FAM: 6-carboxy-fluorescein; NFQ: non-fluorescent quencher; LOD: limits of detection. \\ Authors' contributions \\ JQS and YGZ conceived and designed the project. FFZ designed the assays. FFZ and HL performed the experiments and data analysis. FFZ and JQS wrote the manuscript. XYZ, JQS and YGZ revised the manuscript. All authors read and approved the final manuscript.}

\section{Author details}

${ }^{1}$ Key Lab of Urban Environment and Health, Institute of Urban Environment, Chinese Academy of Sciences, 1799 Jimei Road, Xiamen 361021, China. ${ }^{2}$ University of Chinese Academy of Sciences, Beijing 100049, China.

\footnotetext{
Acknowledgements

We thank Professor Michael Gillings from Macquarie university, Australia, for reviewing and commenting on the manuscript. We thank all volunteers for their assistance in collection of fecal and field samples. This work was financially supported by the National Key Research and Development Plan (2016YFD0800205), the Knowledge Innovation Program of the Chinese Academy of Sciences (IUEQN201504, IUEMS201403) and the International Science \& Technology Cooperation Program of China (2011DFB91710).
}

\section{Competing interests}

The authors declare that they have no completing interests.

\section{Availability of data and materials}

The datasets supporting the conclusions of this article are included within the article.

\section{Consent for publication}

Consent to publish has been obtained from the participants.

\section{Ethical approval}

Fecal sample collection was approved by the Institutional Human and Animal Ethics Committee of Institute of Urban Environment, Chinese Academy of Sciences, and all experiments were carried out in accordance with the approved guidelines.

\section{Funding}

This study was funded by the National Key Research and Development Plan (2016YFD0800205), the Knowledge Innovation Program of the Chinese Academy of Sciences (IUEQN201504, IUEMS201403) and the International Science \& Technology Cooperation Program of China (2011DFB91710).

\section{Publisher's Note}

Springer Nature remains neutral with regard to jurisdictional claims in published maps and institutional affiliations.

Received: 15 February 2017 Accepted: 31 March 2017

Published online: 14 April 2017

\section{References}

Andreasson H, Gyllensten U, Allen M (2002) Real-time DNA quantification of nuclear and mitochondrial DNA in forensic analysis. Biotechniques 33(2):402-411

Blanch AR, Belanche-Munoz L, Bonjoch X, Ebdon J, Gantzer C, Lucena F, Ottoson J, Kourtis C, Iversen A, Kuhn I, Moce L, Muniesa M, Schwartzbrod J, Skraber S, Papageorgiou GT, Taylor H, Wallis J, Jofre J (2006) Integrated analysis of established and novel microbial and chemical methods for microbial source tracking. Appl Environ Microbiol 72(9):5915-5926. doi:10.1128/Aem.02453-05

Boehm AB, Van De Werfhorst LC, Griffith JF, Holden PA, Jay JA, Shanks OC, Wang D, Weisberg SB (2013) Performance of forty-one microbial source tracking methods: a 27 lab evaluation study. Water Res 47(18):6812-6828. doi:10.1016/j.watres.2012.12.046

Caldwell JM, Raley ME, Levine JF (2007) Mitochondrial multiplex real-time PCR as a source tracking method in fecal-contaminated effluents. Environ Sci Technol 41(9):3277-3283. doi:10.1021/es062912s

Caldwell J, Payment P, Villemur R (2011) Microbial source tracking: methods, applications, and case studies. Springer, New York

Chen Q, An X, Li H, Su J, Ma Y, Zhu YG (2016) Long-term field application of sewage sludge increases the abundance of antibiotic resistance genes in soil. Environ Int 92-93:1-10. doi:10.1016/j.envint.2016.03.026

Dancer D, Baker-Austin C, Lowther JA, Hartnell RE, Lees DN, Roberts LO (2014) Development and integration of quantitative real-time PCR methods for detection of mitochondrial DNA and Methanobrevibacter smithii nifH gene as novel microbial source tracking tools. Environ Forensics 15(3):256-264. doi:10.1080/15275922.2014.930762

David LA, Maurice CF, Carmody RN, Gootenberg DB, Button JE, Wolfe BE, Ling AV, Devlin AS, Varma Y, Fischbach MA, Biddinger SB, Dutton RJ, Turnbaugh PJ (2014) Diet rapidly and reproducibly alters the human gut microbiome. Nature 505(7484):559-563. doi:10.1038/nature12820

Ebentier DL, Hanley KT, Cao YP, Badgley BD, Boehm AB, Ervin JS, Goodwin KD, Gourmelon M, Griffith JF, Holden PA, Kelty CA, Lozach S, McGee C, Peed LA, Raith M, Ryu H, Sadowsky MJ, Scott EA, Domingo JS, Schriewer A, Sinigalliano CD, Shanks OC, Van De Werfhorst LC, Wang D, Wuertz S, Jay $J(2013)$ Evaluation of the repeatability and reproducibility of a suite of qPCR-based microbial source tracking methods. Water Res 47(18):68396848. doi:10.1016/j.watres.2013.01.060 
Field KG, Samadpour M (2007) Fecal source tracking, the indicator paradigm, and managing water quality. Water Res 41(16):3517-3538. doi:10.1016/j. watres.2007.06.056

Gómez-Doñate M, Ballesté E, Muniesa M, Blanch AR (2012) New molecular quantitative PCR assay for detection of host-specific Bifidobacteriaceae suitable for microbial source tracking. Appl Environ Microbiol 78(16):5788-5795. doi:10.1128/AEM.00895-12

Green HC, Haugland RA, Varma M, Millen HT, Borchardt MA, Field KG, Walters WA, Knight R, Sivaganesan M, Kelty CA, Shanks OC (2014a) Improved HF183 quantitative real-time PCR assay for characterization of human fecal pollution in ambient surface water samples. Appl Environ Microbiol 80(10):3086-3094. doi:10.1128/AEM.04137-13

Green HC, White KM, Kelty CA, Shanks OC (2014b) Development of rapid canine fecal source identification PCR-based assays. Environ Sci Technol 48:11453-11461. doi:10.1021/es502637b

Harwood VJ, Staley C, Badgley BD, Borges K, Korajkic A (2014) Microbial source tracking markers for detection of fecal contamination in environmental waters: relationships between pathogens and human health outcomes. FEMS Microbiol Rev 38:1-40. doi:10.1111/1574-6976.12031

He X, Chen H, Shi W, Cui Y, Zhang XX (2015) Persistence of mitochondrial DNA markers as fecal indicators in water environments. Sci Total Environ 533:383-390. doi:10.1016/j.scitotenv.2015.06.119

Hofacre CL, Rene'de Cotret A, Maurer JJ, Garritty A, Thayer SG (2000) Presence of fluoroquinolone-resistant coliforms in poultry litter. Avian Dis 44:963-967. doi:10.2307/1593073

lyengar V, Albaugh GP, Lohani A, Nair PP (1991) Human stools as a source of viable colonic epithelial-cells. FASEB J 5:2856-2859

Kildare BJ, Leutenegger CM, MCSwain BS, Bambic DG, Rajal VB, Wuertz S (2007) $16 \mathrm{~S}$ rRNA-based assays for quantitative detection of universal, human-, cow-, and dog-specific fecal Bacteroidales: a Bayesian approach. Water Res 41:3701-3715. doi:10.1016/j.watres.2007.06.037

Kobayashi A, Sano D, Hatori J, Ishii S, Okabe S (2013) Chicken- and duck-associated Bacteroides-Prevotella genetic markers for detecting fecal contamination in environmental water. Appl Microbiol Biotechnol 97:7427-7437. doi:10.1007/s00253-012-4469-2

Larkin MA, Blackshields G, Brown NP, Chenna R, McGettigan PA, McWilliam H, Valentin F, Wallace IM, Wilm A, Lopez R, Thompson JD, Gibson TJ, Higgins DG (2007) Clustal W and Clustal X version 2.0. Bioinformatics 23(21):29472948. doi:10.1093/bioinformatics/btm404

Layton A, McKay L, Williams D, Garrett V, Gentry R, Sayler G (2006) Development of Bacteroides 165 rRNA gene TaqMan-based real-time PCR assays for estimation of total, human, and bovine fecal pollution in water. Appl Environ Microbiol 72:4214-4224. doi:10.1128/AEM.01036-05

Martellini A, Payment P, Villemur R (2005) Use of eukaryotic mitochondrial DNA to differentiate human, bovine, porcine and ovine sources in fecally contaminated surface water. Water Res 39:541-548. doi:10.1016/j. watres.2004.11.012

Marti R, Zhang Y, Lapen DR, Topp E (2011) Development and validation of a microbial source tracking marker for the detection of fecal pollution by muskrats. J Microbiol Methods 87:82-88. doi:10.1016/j.mimet.2011.07.013

McLellan SL, Eren AM (2014) Discovering new indicators of fecal pollution. Trends Microbiol 22:697-706. doi:10.1016/j.tim.2014.08.002

McMurry SW, Coyne MS, Perfect E (1998) Fecal coliform transport through intact soil blocks amended with poultry manure. J Environ Qual 27:86-92

Moritz C, Dowling TE, Brown WM (1987) Evolution of animal mitochondrialDNA-relevance for population biology and systematics. Annu Rev Ecol Syst 18:269-292. doi:10.1146/annurev.ecolsys.18.1.269
Muegge BD, Kuczynski J, Knights D, Clemente JC, Gonzalez A, Fontana L, Henrissat B, Knight R, Gordon II (2011) Diet drives convergence in gut microbiome functions across mammalian phylogeny and within humans. Science 332(6032):970-974. doi:10.1126/science.1198719

Ohad S, Ben-Dor S, Prilusky J, Kravitz V, Dassa B, Chalifa-Caspi T, Kashi Y, Rorman E (2016) The development of a novel qPCR assay-set for identifying fecal contamination originating from domestic fowls and waterfowl in Israel. Front Microbiol. doi:10.3389/fmicb.2016.00145

Owczarzy R, Tataurov AV, Wu Y, Manthey JA, McQuisten KA, Almabrazi HG, Pedersen KF, Lin Y, Garretson J, McEntaggart NO, Sailor CA, Dawson RB, Peek AS (2008) IDT SciTools: a suite for analysis and design of nucleic acid oligomers. Nucleic Acids Res 36(2):163-169. doi:10.1093/nar/gkn198

Parveen S, Murphree RL, Edmiston L, Kaspar CW, Portier KM, Tamplin ML (1997) Association of multiple-antibiotic-resistance profiles with point and nonpoint sources of Escherichia coli in Apalachicola bay. Appl Environ Microbiol 63:2607-2612

Ryu H, Griffith JF, Khan IU, Hill S, Edge TA, Toledo-Hernandez C, GonzalezNieves J, Santo DJ (2012) Comparison of gull feces-specific assays targeting the 16S rRNA genes of Catellicoccus marimammalium and Streptococcus spp. Appl Environ Microbiol 78(6):1909-1916. doi:10.1128/ AEM.07192-11

Ryu H, Elk M, Khan IU, Harwood VJ, Molina M, Edge TA, Domingo JS (2014) Comparison of two poultry litter qPCR assays targeting the $16 \mathrm{~S}$ rRNA gene of Brevibacterium sp. Water Res 48:613-621. doi:10.1016/j. watres.2013.10.015

Schill WB, Mathes MV (2008) Real-time PCR detection and quantification of nine potential sources of fecal contamination by analysis of mitochondrial cytochrome $b$ targets. Environ Sci Technol 42:5229-5234 doi:10.1021/es800051z

Scott TM, Rose JB, Jenkins TM, Farrah SR, Lukasik J (2002) Microbial source tracking: current methodology and future directions. Appl Environ Microb 68:5796-5803. doi:10.1128/AEM.68.12.5796-5803.2002

Simpson JM, Santo Domingo JW, Reasoner DJ (2002) Microbial source tracking: state of the science. Environ Sci Technol 36:5279-5288. doi:10.1021/ es026000b

Tambalo DD, Boa T, Liljebjelke K, Yost CK (2012) Evaluation of two quantitative PCR assays using Bacteroidales and mitochondrial DNA markers for tracking dog fecal contamination in waterbodies. J Microbiol Methods 91:459-467. doi:10.1016/j.mimet.2012.09.029

Turnbaugh PJ, Ridaura VK, Faith JJ, Rey FE, Knight R, Gordon JI (2009) The effect of diet on the human gut microbiome: a metagenomic analysis in humanized gnotobiotic mice. Sci Transl Med. doi:10.1126/ scitranslmed.3000322

WHO Scientific group (2000) Global water supply and sanitation assessment 2000 report. World Health Organization, Geneva

WHO Scientific group (2011) Guidelines for drinking-water quality, 4th edn. World Health Organization, Geneva

Wiggins BA (1996) Discriminant analysis of antibiotic resistance patterns in fecal streptococci, a method to differentiate human and animal sources of fecal pollution in natural waters. Appl Environ Microb 62:3997-4002

Wu GD, Chen J, Hoffmann C, Bittinger K, Chen YY, Keilbaugh SA, Bewtra M, Knights D, Walters WA, Knight R, Sinha R, Gilroy E, Gupta K, Baldassano R, Nessel L, Li HZ, Bushman FD, Lewis JD (2011) Linking long-term dietary patterns with gut microbial enterotypes. Science 334(6052):105-108. doi:10.1126/science.1208344 